\title{
WLB in Zahlen 2019
}

\begin{tabular}{|c|c|}
\hline \multicolumn{2}{|l|}{ Gesamtbestand (Stand: 13.3.2020) } \\
\hline Medienbestand insgesamt & 6.178 .562 \\
\hline \multicolumn{2}{|l|}{ davon: } \\
\hline Buchmaterialien & 4.124 .475 \\
\hline Autographen & 180.649 \\
\hline Handschriften & 15.570 \\
\hline Inkunabeln & 7.093 \\
\hline Noten & 74.878 \\
\hline Karten & 157.447 \\
\hline Mikroformen & 487.943 \\
\hline AV-Materialien (Ton-, Bildträger) & 48.813 \\
\hline CD-ROMS & 29.377 \\
\hline Flugblätter & 160.960 \\
\hline Fotos & 584.766 \\
\hline Plakate & 40.217 \\
\hline Feldpostbriefe & 149.376 \\
\hline Porträts & 36.926 \\
\hline $\begin{array}{l}\text { davon: Varia 3.480, Disketten 3.391, Ortsansichten 8.583, Ansichtskarten 37.396, Ereignisdarstellungen 2.000, } \\
\text { Sonstiges Sig. Nicolai 22.000, Einblattmat./Sonstige 3.061, Nachlässe } 161\end{array}$ & 80.072 \\
\hline Bibeln (in 764 Sprachen) & 21.295 \\
\hline Lfd. geh. Zeitschriften u. Zeitungen (Abos) & 8.848 \\
\hline Angebot an elektronischen Zeitschriften & 27.525 \\
\hline Angebot an online-Datenbanken & 329 \\
\hline Angebot an E-Books & 57.651 \\
\hline Zugang 2019 & 49.637 \\
\hline Kauf & 21.023 \\
\hline Pflicht & 24.824 \\
\hline Tausch & 153 \\
\hline Geschenk & 3.637 \\
\hline \multicolumn{2}{|l|}{ Benutzung 2019} \\
\hline Öffnungstage & 291 \\
\hline Öffnungsstunden pro Woche & 64 \\
\hline Entleihungen insgesamt & 1.230 .109 \\
\hline Aktive Entleiher & 25.220 \\
\hline Benutzerfälle in den Lesesälen & 256.200 \\
\hline Benutzerschulungen / Führungen (Stunden) & 308,33 \\
\hline Fernleihbestellungen (aktiv, pos. erledigt) & 32.528 \\
\hline Fernleihbestellungen (passiv, pos. erledigt) & 17.252 \\
\hline Personalstellen 2019 & 129 \\
\hline Kulturelle Veranstaltungen 2019 & 24 \\
\hline Ausstellungen & 8 \\
\hline Weitere Veranstaltungen & 16 \\
\hline
\end{tabular}

